\title{
Rethinking funding priorities in mental health research ${ }^{\dagger}$
}

Roberto Lewis-Fernández, Mary Jane Rotheram-Borus, Virginia Trotter Betts, Lisa Greenman, Susan M. Essock, Javier I. Escobar, Deanna Barch, Michael F. Hogan, Patricia A. Areán, Benjamin G. Druss, Ralph J. Diclemente, Thomas H. McGlashan, Dilip V. Jeste, Enola K. Proctor, Pedro Ruiz, A. John Rush, Glorisa J. Canino, Carl C. Bell, Renata Henry and Portia Iversen

\section{Summary}

Mental health research funding priorities in high-income countries must balance longer-term investment in identifying neurobiological mechanisms of disease with shorter-term funding of novel prevention and treatment strategies to alleviate the current burden of mental illness. Prioritising one area of science over others risks reduced returns on the entire scientific portfolio.

\section{Declaration of interest}

Some authors work in research areas (e.g. optimising interventions for people with mental illnesses) that could receive additional funding if the recommendations for realignment of funding priorities made in the article were implemented. Specific conflicts of interest: R.L.-F., National Alliance on Mental Illness, Eli Lilly \& Co, American Psychiatric Association, Cambridge University Press, UptoDate and American Psychiatric Publishing Inc.; D.B., Pfizer, Roche, Takeda, Amgen; M.F.H., Otsuka, Education Development Center, Policy Research Associates; A.J.R., Medavante, Takeda, Eli Lilly \& Co, Santium Inc.

\section{Copyright and usage}

(C) The Royal College of Psychiatrists 2016. This is an open access article distributed under the terms of the Creative Commons Non-Commercial, No Derivatives (CC BY-NC-ND) licence.
Roberto Lewis-Fernández (pictured) is Professor of Psychiatry at Columbia University Medical Center and Director of the New York State Center of Excellence for Cultural Competence. Mary Jane Rotheram-Borus designs and evaluates interventions at UCLA with children and families for multiple negative outcomes - HIV , substance abuse, suicide and homelessness. Virginia Trotter Betts served as Tennessee's Commissioner of Behavioral Health, and President of the National Association of Mental Health Program Directors and the American Nurses Association. Lisa Greenman, a lawyer in Washington, DC, specialises in mental health and developmental disability issues that affect criminal defendants. Susan M. Essock is the Edna L. Edison Professor of Psychiatry, Columbia University and the founding Director of the Center for Practice Innovations there. Javier I. Escobar is Senior Associate Dean for Global Health and Professor of Psychiatry and Family Medicine at Rutgers-Robert Wood Johnson Medical School. Deanna Barch is the Chair of Psychological and Brain Sciences and Gregory Couch Chair of Psychiatry at Washington University in St Louis. Michael Hogan served as mental health commissioner in three states (1987-2012) and was chairman of the 20022003 President's New Freedom Commission on Mental Health. Patricia Areán is an internationally known expert in the development and study of behavioral treatments for mood disorders in older adults and underserved populations. Benjamin Druss is Professor and Rosalynn Carter Chair in Mental Health in the Rollins School of Public Health at Emory University. Ralph DiClemente is Charles Howard Candler Professor, Rollins School of Public Health, Emory University, focusing on the development and evaluation of HIV/STD riskreduction programmes. Thomas McGlashan is Professor of Psychiatry at Yale University School of Medicine and on the medical staff of the Connecticut Mental Health Center. Dilip V. Jeste is Senior Associate Dean for Healthy Aging and Senior Care and Distinguished Professor of Psychiatry and Neurosciences at University of California, San Diego. Enola K. Proctor is Shanti Khinduka Distinguished Professor, Brown School of Social Work, and Director, Center for Mental Health Services Research, Washington University in St Louis. Pedro Ruiz is Professor of Psychiatry at the University of Miami and past President of the American Psychiatric Association and the World Psychiatric Association. A. John Rush is Professor Emeritus at the National University of Singapore. He has authored over 600 peer-reviewed articles and 80 book chapters on mood disorders. Glorisa Canino is the director of the Behavioral Sciences Research Institute at the University of Puerto Rico Medical School. Carl Bell is the former Director of the Institute for Juvenile Research and retired Professor of Psychiatry and Public Health at University of Illinois-Chicago. Renata Henry is Project Director of the SAMHSA-funded US Health and Human Services Region 3 Addiction Technology Transfer Center. Portia Iversen is co-founder of Cure Autism Now, an autism research foundation, and the Autism Genetic Resource Exchange, the first open-resource autism gene bank.
In the USA the National Institute of Mental Health (NIMH) is undergoing its first leadership transition in 13 years. With an annual budget of 1.4 billion US dollars, this transition presents a critical opportunity to examine US mental health research funding priorities. Balancing research investments between projects that investigate ways to alleviate the current burden of disease and those that seek scientific breakthroughs leading to future cures is a challenge each country must address. ${ }^{1,2}$ As current or former members of the NIMH National Advisory Mental Health Council, we have repeatedly reflected on changing emphases in NIMH funding priorities. We offer these reflections in the hope of influencing NIMH policy and to add to the international conversation on mental health research funding priorities, given the impact of NIMH as the world's largest funder of research on mental disorders.

The USA and other high-income countries have an ongoing need to examine these priorities. Despite spending more than any other country on healthcare (4271 US dollars annually/ person), the USA ranks 37 th in global health outcomes and fails to serve even half of its residents needing mental health services. ${ }^{3}$ As recently as 2015, an Institute of Medicine report decried the quality of mental healthcare in the USA. Americans' national provision of mental health prevention and treatment services needs an overhaul and research should guide this process. The USA is not alone in this challenge. Globally, 450 million people with mental health problems are underserved, ${ }^{2}$ and countries across the economic spectrum need research to inform healthcare policy on how to prevent and treat mental illnesses within resource constraints.

\section{The role of neuroscience in the solution}

In recent years, the NIMH funding allocation has prioritised searching for neurobiological mechanisms of mental illness,

†See commentary, pp. 510-511, this issue. 
seeking a new world of personalised medicine. The expectation is that identifying an individual's biological signature at genomic and neurocircuitry levels will generate novel prevention and treatment interventions. Growth in neuroscience investment at US federal granting agencies has been impressive, including President Obama's BRAIN initiative and targeted funds such as innovation awards, molecular libraries and the Research Domain Criteria initiative (a reframing of the research paradigm towards understanding mechanisms of mental illness). Other high-income countries have also prioritised neuroscience research, including the European Commission's Human Brain Project, Japan's Brain/MINDS project and Australia's AusBrain. ${ }^{4}$ Currently, the number of new PhDs in neuroscience outstrips all other life sciences, heralding a 'golden age of neuroscience. ${ }^{5}$

Neuroscience is unquestionably crucial for mental health. Discovering causes of autism or pathophysiologies of diverse illnesses encompassed by the diagnosis of schizophrenia opens possibilities for new treatments. Still, investing in neuroscience is a long-term proposition. Although the USA 'Decade of the Brain' ${ }^{4}$ began in 1990, substantial public health benefits are yet to be realised. ${ }^{6}$ Hence the key question remains: how can funding policy in mental health research improve how we tackle the current burden of disease as we await innovations derived through advances in neuroscience that may be generations away?

\section{Opportunity costs}

Mental health research funding is a form of social investment. ${ }^{1}$ As with any investment portfolio, diversification is a prudent strategy. A disproportionate investment in neuroscience is as imprudent as investing only in growth stocks and neglecting less risky investments that yield immediate albeit potentially more modest benefits. Publicly funded government agencies are custodians of research for the public good. A diversified research portfolio, balanced between longer- and shorter-term pay-outs, has the advantage of demonstrating to stakeholders a present and steady payoff in improvements to routine practice. Fortunately, the services-research end of the NIMH portfolio provides such examples today. When outgoing NIMH Director Insel gave his final top ten list of best mental health research stories for the year, his pick for number one was from the services-research portfolio, noting, 'this year we saw a spectacular example of how to move research into practice... The Recovery After an Initial Schizophrenia Episode (RAISE) project developed a patientcentred, multi-element treatment approach for optimising outcomes after a first episode of psychosis." Although NIMH support for projects like RAISE continues, those funding levels are dwarfed by neuroscience-related investments. As presented at open access Council meetings, yearly total investment in nonHIV/AIDS services and interventions research since 2012 comprises $\sim 15 \%$ of the NIMH budget, with basic and translational neuroscience research accounting for the remaining $85 \%$.

To prioritise one area of science over others risks compromising the overall return-on-investment. Neuroscience is one road to improving mental health, but overenthusiasm for this area means losing opportunities for advancements in mental health through research in areas such as developing sustainable interventions to overcome disparities in access to effective treatment and outcomes; crafting technologies and implementation strategies to disseminate scalable, cost-efficient interventions; devising approaches to empower people to overcome barriers to engagement and retention in treatment; and deploying preventive interventions to reduce the burden of mental illness, including clarifying how to implement best practices in suicide prevention, especially given the dramatic rise in suicide. Scalability of prevention interventions is key. Solutions may leverage technological advances, such as mHealth-based counselling, computer and web-based resources and collaboration with caregivers - such as teachers, clergy and primary care providers - who are first points-of-contact for those in need.

When NIMH leaders sought to illustrate the limited impact of mental health research on public health, they compared the multiple-decade decline in cardiovascular mortality with an increasing suicide rate, citing our limited understanding of mechanisms and the lack of new treatment agents as barriers to progress. Yet, epidemiological explanations of the decline in cardiovascular mortality find that lifestyle changes affecting risk factors (such as smoking) account for $44-76 \%$ of decreased mortality, whereas novel treatments account for $23-47 \%{ }^{8}$ Research on how to develop and implement preventive (including early-detection) mental health interventions could have similarly salutatory effects. For instance, a substantial proportion of children's emotional impairments and poor school functioning could be alleviated by improving parenting skills, learning environments and habits of daily living. ${ }^{9}$ Prevention research should also identify strategies for mitigating the effects of social determinants and physical environments triggering mental illness. Pursuing these opportunities would result in a more diversified portfolio of intervention development, dissemination and implementation than currently exists.

In sum, too often our mental health research funding neglects immediate public health needs to focus on future discoveries, reflecting the drive for technological solutions for disorders that are unequally distributed and partly socially determined. Time frames for such payoffs have previously been consistently underestimated, underscoring the prudence of keeping a healthy portion of the research portfolio invested in projects with shorter-term benefits.

\section{Finding the right balance}

Ultimately, what is the right funding balance between neuroscience and applied research? Ensuring that the mental health research portfolio yields steady payoffs independent of the pay-outs that come with scarce scientific breakthroughs requires investing a more substantial proportion of the research portfolio in developing novel applied treatments, such as RAISE, and to the science of how to implement basic science advances, including how to tailor them across diverse clinical settings and communities. Research must be funded to overcome barriers at every level - from systems to patient-level factors - that limit the use and effectiveness of interventions, including through prevention/early-intervention strategies and therapies for those already ill.

Public health has always been a cornerstone of the NIMH mandate. One of its foundational documents, the Action for Mental Health Report of 1960, defined the agency's mission as 'arriv[ing] at a national program that would approach adequacy in meeting the individual needs of the mentally ill people of America. ${ }^{10}$ NIMH research must advance current prevention and care delivery strategies, even as it races towards a cure. En-route, NIMH should fund research to evaluate the evidence base and make practice recommendations feasible to implement in routine practice settings. Such standards could be used by states and other payers as they hold managed care organisations and other provider groups accountable. Broadly in US health policy, an emerging consensus calls for health in all policies, mental health in all health, and attention to the social determinants of 
health. The recent distribution of funding from NIMH suggests that these concepts need increased attention, priority and dollars.

\section{Next steps}

We call for an increase in public discussion of how to apportion funding resources across mental health research domains, as broad participation by stakeholders can lead to new policy priorities. This conversation should be fostered within national and international health organisations, government funding agencies such as the NIMH, and professional journals and organisations as well as in public forums, legislative hearings and political debates. These discussions must address thorny details, such as what proportion of the budget should be allocated to what research areas; the near-term public health consequences of particular priorities; and how to leverage inter-agency collaborations to attain a robust and sustainable public health impact. The conversation should be international in scope. The NIMH can contribute to, and benefit from, the global discussion on funding policy conducted by organisations like the Roadmap for Mental Health Research and Well-Being in Europe, the Global Mental Health Initiative, Horizon 2020 and Grand Challenges Canada. Paramount in these discussions must be alleviating the terrible burden that individuals and families living with mental illness face every day. As Harry Hopkins, co-architect of the 1940s New Deal, replied to members of Congress who opposed allocating federal funds to lift the economy out of the Great Depression, claiming that the economy would sort itself out 'in the long run': 'People don't eat in the long run, they eat every day'.

\section{Acknowledgements}

The authors appreciate the assistance of David A. Brent, Dolly John, Maryann E. Koussa, Samantha Díaz, Myrna Weissman and John Markowitz.

\section{References}

1 Hoddinott J, Rosegrant M, Torero M (eds). Investments to Reduce Hunger and Undernutrition: Copenhagen Consensus 2012: Solving the World's Challenges. International Food Policy Research Institute of Washington DC, 2012.

2 World Health Organization (WHO). Investigating in Mental Health. WHO, 2003 (http://www.who.int/mental_health/media/investing_mnh.pdf).

3 Murray $\mathrm{CJL}$, Frenk J. Ranking 37th-measuring the performance the US health care system. N Engl J Med 2010; 362: 98-9.

4 Society for Neuroscience. Science Funding Resources. Society for Neuroscience, 2015 (http://www.sfn.org/advocacy/neuroscience-funding/ worldwide-neuroscience-initiatives).
Roberto Lewis-Fernández, MD, Columbia University Medical Center, and New York State Center of Excellence for Cultural Competence, and Hispanic Treatment Program, at the New York State Psychiatric Institute, New York, USA; Mary Jane Rotheram-Borus, PhD, Department of Psychiatry and Biobehavioral Sciences, Semel Institute, University of California at Los Angeles, Los Angeles, California, USA; Virginia Trotter Betts, MSN, JD, RN, HealthFutures, Inc., Nashville, Tennessee, USA; Lisa Trotter Betts, MSN, JD, RN, HealthFutures, Inc., Nashville, Tennessee, USA; Lisa
Greenman, JD, Attorney At Law, Washington, DC, USA; Susan M. Essock, PhD, Columbia University Medical Center, New York, USA; Javier I. Escobar, MD, RutgersRobert Wood Johnson Medical School, New Brunswick, New Jersey, USA; Deanna Barch, PhD, Washington University in St Louis, St Louis, Missouri, USA; Michael F. Hogan, PhD, Dartmouth (Geisinger) Medical School, Case Western Reserve Medical School, and New York University Medical School, and Hogan Health Solutions, New York, USA; Patricia A. Areán, PhD, Department of Psychiatry and Behavioral Sciences, University of Washington, Seattle, Washington, USA; Benjamin G. Druss MD, MPH, Ralph J. Diclemente, PhD, Rollins School of Public Health, Emory University, Atlanta, Georgia, USA; Thomas H. McGlashan, MD, Yale University School of Medicine, and Connecticut Mental Health Center, New Haven, Connecticut, USA; Dilip V. Jeste, MD, Sam and Rose Stein Institute for Research on Aging, University of California San Diego, San Diego, California, USA; Enola K. Proctor, PhD, Brown School of Social Work, and Center for Mental Health Services Research, Washington University in St Louis, St Louis, Missouri, USA; Pedro Ruiz, MD,

Department of Psychiatry \& Behavioral Sciences, Miller School of Medicine, University of Miami, Miami, Florida, USA; A. John Rush, MD, Duke-National University of Singapore, and Duke Medical School, Santa Fe, New Mexico, USA; Glorisa J. Canino, $\mathrm{PhD}$, Behavioral Sciences Research Institute, and Department of Pediatrics, University of Puerto Rico Medical School, San Juan, Puerto Rico; Carl C. Bell, MD, Jackson Park Hospital, Family Medicine Clinic, Chicago, Illinois, USA; Renata Henry, Med, Danya Institute, and Central East Addiction Technology Transfer Center, Newark, Delaware, USA; Portia Iversen, BFA, Cure Autism Now, and Autism Genetic Resource Exchange, Los Angeles, California, USA

Correspondence: Roberto Lewis-Fernández, MD, Director, New York State Center of Excellence for Cultural Competence, and Hispanic Treatment Program, at the New York State Psychiatric Institute, Unit 69, Room 3206, 1051 Riverside Drive, New York, NY 10032, USA. Email: rlewis@nyspi.columbia.edu.

First received 10 Dec 2015, final revision 18 Mar 2016, accepted 29 Mar 2016

5 Norris SMP, Palmer C, Stroud C, Altevogt BM, Forum on Neuroscience and Nervous System Disorders, Board on Health Science Policy, Institute of Medicine. Developing a 21st Century Neuroscience: Workshop Summary. National Academies Press, 2015.

6 Priebe S, Burns T, Craig TK. The future of academic psychiatry may be social. Br J Psychiatry 2013; 202: 319-20.

7 Insel T. Director's Blog. National Institute of Mental Health, 2014 (http://www.nimh.nih.gov/about/director/2014/best-of-2014.shtml).

8 Ford ES, Capewell S. Proportion of the decline in cardiovascular mortality disease due to prevention versus treatment: public versus clinical care. Annu Rev Public Health 2011; 32: 5-22.

9 World Bank Group. Chapter 5: Early childhood development. In World Development Report 2015: Mind, Society, and Behavior. World Bank, 2015 (http://www.worldbank.org/content/dam/Worldbank/Publications/WDR/ WDR\%202015/Chapter-5.pdf).

10 National Institutes of Health. The NIH Almanac: National Institute of Mental Health. NIH, 2015 (http://www.nih.gov/about-nih/what-we-do/ nih-almanac/national-institute-mental-health-nimh).

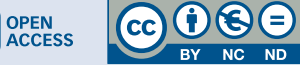

